\title{
Ultrasonication impregnation of Florisil with 1-octyl-3-methylimidazolium tetrafluoroborate used as an adsorbent in the removal process of $\mathrm{Cs}^{+}$from aqueous solutions
}

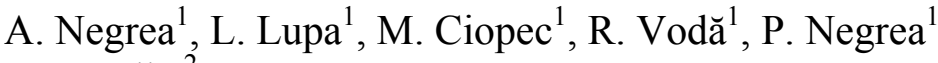 \\ \& I. Hulka ${ }^{2}$ \\ ${ }^{I}$ Politehnica University Timisoara, \\ Faculty of Industrial Chemistry and Enviromental Engineering, Romania \\ ${ }^{2}$ Politehnica University Timisoara, \\ Office Accounting and Monitoring of Research, Development and \\ Innovation Contracts, Romania
}

\begin{abstract}
The present paper presents the studies regarding the impregnation conditions through ultrasonication of 1-Octyl-3-methylimidazolium tetrafluoroborate[OmimBF4] onto Florisil support in order to enhance the adsorption efficiency of the resulting adsorbent. The obtained Florisil impregnated with [OmimBF4] in various work conditions of ultrasonication was subjected to a complex characterization scanning electron microscopy (SEM), energy dispersive X-ray analysis (EDX) and Fourier transform infrared spectroscopy (FTIR) and was used as an adsorbent in the removal process of $\mathrm{Cs}^{+}$from aqueous solutions. In order to obtain a stable and homogenous impregnation of the solid support surface which will achieve reproducible results in the adsorption processes, it is not necessary to increase the ultrasonication time, but we should use higher amplitude. The impregnated material obtained in the recommended conditions showed good adsorption performance in the removal process of $\mathrm{Cs}^{+}$from aqueous solutions, developing a maximum adsorption capacity of $2.27 \mathrm{mg} / \mathrm{g}$. Keywords: ultrasonication, impregnation, ionic liquid, Florisil, $\mathrm{Cs}^{+}$adsorption .
\end{abstract}




\section{Introduction}

Radioactive waste can affect human health and the environment, therefore, the management and disposal of such waste is an issue relevant to almost all countries [1-4]. In recent years, the researchers focused on the applications of ionic liquids (ILs) as new separation media of metals from aqueous solutions, instead of organic solvent use, due to their well known advantages [5-9]. It was observed that through impregnation of the ionic liquid onto a suitable solid support, a higher efficiency in the removal process of metals ions from aqueous solutions is obtained, because it favorably combines the properties of ILs with the advantages of solid supports [10-13]. Many methods of extractant impregnation onto various solid supports were studied in the literature, such as the dry method of impregnation [6, 9, 12-14], encapsulation [15], sol-gel method $[7,16]$ and chemical immobilization $[17,18]$. All these mentioned methods are quite time consuming; therefore, in this paper a new impregnation method which needs a shorter time for the impregnation of an ionic liquid onto a solid support is studied. This method is the ultrasonication method. Kalidhasan used this method for the impregnation of IL onto Dowex resin used in the removal process of $\mathrm{Cr}(\mathrm{VI})$ from aqueous solutions [19]. The ultrasonication method and the work conditions were highly studied and used for the obtaining of various catalysts $[20,21]$. Also, in our previous study, a comparison between various methods of IL impregnation onto inorganic solid support (dry method, stirring method, the wet impregnation method and ultrasonication) showed that the ultrasonication method presents the highest efficiency in the removal process of metals ions from aqueous solutions [22]. In this paper the influence of the work conditions of the ultrasonication method upon the adsorption performance of the obtained materials was studied in order to determine the optimum conditions of impregnation which enhance the adsorption properties of the impregnated materials. The work conditions of the ultrasound method were studied in the process of 1-Octyl-3-methylimidazolium tetrafluoroborate-[OmimBF4] impregnation onto Florisil. This ionic liquid was chosen because the imidazolium based ionic liquids were intensively investigated in literature and showed higher stability [23-25]. An inorganic one was chosen as solid supports due to it having a highly porous texture and a large specific surface area. In our previous studies it was observed that the inorganic solid supports present higher efficiency over the organic supports in the adsorption process of radionuclides [4]. The obtained Florisil impregnated with [OmimBF4] in various work conditions of ultrasonication was subjected to a complex characterization scanning electron microscopy (SEM), energy dispersive X-ray analysis (EDX) and Fourier transform infrared spectroscopy (FTIR) and was used as an adsorbent in the removal process of $\mathrm{Cs}^{+}$from aqueous solutions.

\section{Experimental}

For the impregnation of the Florisil with the studied IL, the time of ultrasonication (10-60 minutes) and the amplitude (10-100\%) using a Sonorex 
Super 10P ultrasonic bath, was varied. In all the experiments, the ratio between the ionic liquid and solid support was kept at 0.1:1. Scanning Electron Microscopy (SEM) was used in order to investigate the changes of the surface morphology of the obtained adsorbent function of the impregnation conditions. SEM images were recorded using a Quanta FEG 250 microscope, equipped with an EDAX ZAF quantifier. The FTIR spectra (KBr pellets) of the obtained materials were recorded on a Shimadzu Prestige- 21 FTIR spectrophotometer in the range $4000-400 \mathrm{~cm}^{-1}$. In order to establish the optimum conditions of impregnation, $0.1 \mathrm{~g}$ of obtained materials were treated with $25 \mathrm{~mL}$ of $10 \mathrm{mg} / \mathrm{L}$ $\mathrm{Cs}^{+}$solutions, obtaining the dependence of the $\mathrm{Cs}^{+}$uptake versus the ultrasonication time and amplitude. In these experiments, the samples were stirred for $1 \mathrm{~h}$ using a Julabo shaker. After the time had elapsed the samples were filtered and the residual concentration of $\mathrm{Cs}^{+}$was analysed through atomic emission spectrometry using a Varian SpectrAA 280 type atomic absorption spectrometer using an air/acetylene flame. The $\mathrm{Cs}^{+}$uptake was expressed using equation (1):

$$
q_{e}=\frac{\left(C_{0}-C_{e}\right) \cdot V}{m}
$$

where: $\mathrm{C}_{0}$ and $\mathrm{C}_{\mathrm{e}}$ are the concentrations of $\mathrm{Cs}^{+}(\mathrm{mg} / \mathrm{L})$ in the solution initially $(t=0)$ and at equilibrium, respectively, $\mathrm{V}$ is the volume of the solution and $\mathrm{m}$ is the mass of adsorbent.

For the Florisil impregnated with [OmimBF4] in the recommended conditions established in the first step of the research, the maximum adsorption capacity in the removal process of $\mathrm{Cs}^{+}$from aqueous solutions was determined. In this aim, the dependence of the $\mathrm{Cs}^{+}$uptake was determined varying the initial concentrations of $\mathrm{Cs}^{+}$from aqueous solutions (range $5-50 \mathrm{mg} / \mathrm{L}$ ) and the obtained results were fitted with well known Langmuir and Freundlich equations.

\section{Results and discussions}

\subsection{Characterization of the impregnated Florisil with [OmimBF4] using various conditions of ultrasonication}

The changes of the morphologies of the Florisil impregnated with [OmimBF4] function of time of ultrasonication using an amplitutde of $100 \%$ are presented in the SEM images from figure 1.

It can be observed that the increasing of the ultrasonication time lead to a patchy conglomeration of the studied IL onto the surface of Florisil support. The most uniform adherence of the IL particle onto the Florisil is obtained in case of 10 minutes of impregnation. Also at this time the adherence is deeper in the particles of the solid support, in this way the leaching of the IL from the solid support surface during the adsorption experiments is avoided. These results are significant in order to obtain reproducibility of the $\mathrm{Cs}^{+}$adsorption process. 
From the SEM images of the materials obtained using various amplitude of ultrasonication and a time of 10 minutes (figure 2) it can be observed that through the amplitude increasing is achieved an easier transmission of the IL particles through the liquid media until reach the cavities of the solid support, the impregnation being realized inside the pore of the solid support. The increasing of the amplitude insures a higher stability of impregnation.

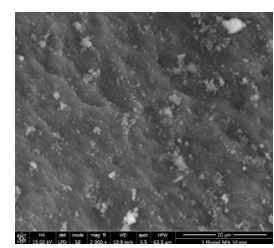

$10 \mathrm{~min}$

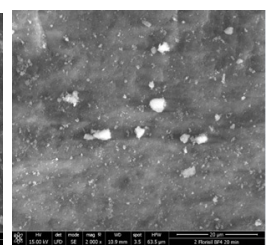

$20 \min$

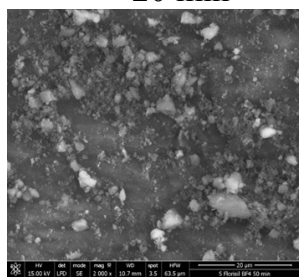

$50 \min$

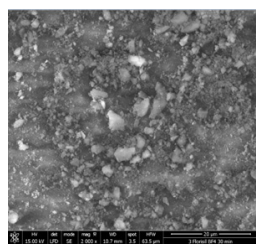

$30 \mathrm{~min}$

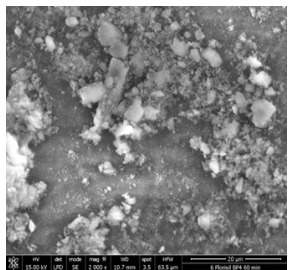

$60 \mathrm{~min}$

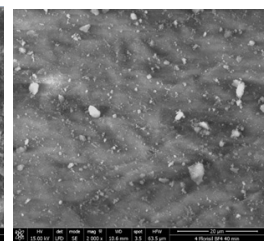

$40 \min$

Figure 1: SEM images of Florisil impregnated with [OmimBF4] using various ultrasonication times.

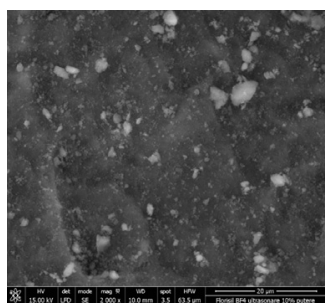

$10 \%$

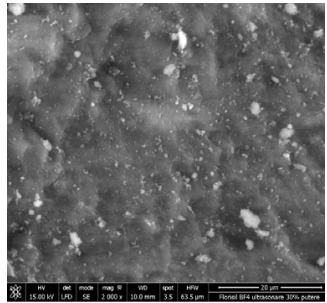

$30 \%$

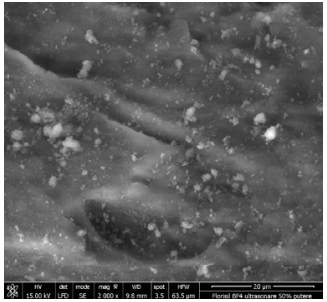

$50 \%$

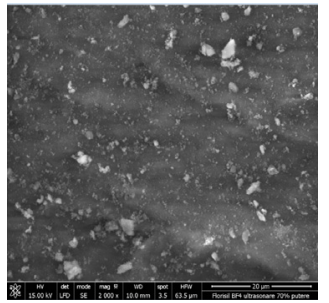

$70 \%$

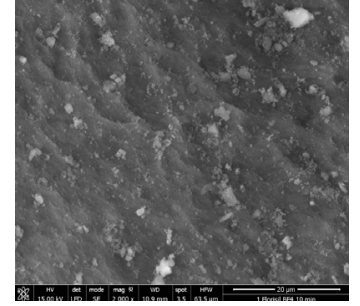

$100 \%$

Figure 2: SEM images of Florisil impregnated with [OmimBF4] using various ultrasonication amplitudes. 
The EDX analysis (Table 1) highlights the conclusions raised from the SEM images. It can be observed that the quantifications of $\mathrm{B}, \mathrm{F}$ and $\mathrm{N}$ (elements specific for the impregnated ionic liquid) are not conclusively influenced by the time of ultrasonication, underlining the fact that by increasing the time an unstable and patchy adherence of the ionic liquid onto the Florisil surface is achieved. On the other hand, increasing the ultrasonication amplitude leads to the increasing of the $\mathrm{B}, \mathrm{F}$ and $\mathrm{N}$ quantifications. These indicate that the highest quantity of the $\left[\mathrm{OmimBF}_{4}\right]$ impregnated onto Florisil support is obtained when the impregnation method through ultrasonication is realized using an amplitude of $100 \%$ for 10 minutes. Because of this, we expect that the adsorbent obtained in these conditions will develop the highest efficiency in the removal process of $\mathrm{Cs}^{+}$from aqueous solutions.

Table 1: The quantification of $\mathrm{B}, \mathrm{F}$ and $\mathrm{N}$ for the obtained impregnated materials resulting from EDX analysis.

\begin{tabular}{|c|c|c|c|c|c|c|c|}
\hline $\begin{array}{c}\text { Time of } \\
\text { ultrasonication } \\
(\mathrm{min})\end{array}$ & $\begin{array}{c}\mathrm{B}, \\
(\mathrm{wt} \\
\%)\end{array}$ & $\begin{array}{c}\mathrm{F}, \\
(\mathrm{wt} \\
\%)\end{array}$ & $\begin{array}{c}\mathrm{N}, \\
(\mathrm{wt} \\
\%)\end{array}$ & $\begin{array}{c}\text { Amplitude of } \\
\text { ultrasonication } \\
(\%)\end{array}$ & $\begin{array}{c}\mathrm{B}, \\
(\mathrm{wt} \\
\%)\end{array}$ & $\begin{array}{c}\mathrm{F}, \\
(\mathrm{wt} \\
\%)\end{array}$ & $\begin{array}{c}\mathrm{N}, \\
(\mathrm{wt} \\
\%)\end{array}$ \\
\hline 10 & 2.82 & 0.13 & 2.21 & 10 & 1.47 & 0.03 & 1.18 \\
\hline 20 & 2.32 & 0.06 & 1.53 & 30 & 2.60 & 0.03 & 1.63 \\
\hline 30 & 2.25 & 0.05 & 1.42 & 50 & 2.74 & 0.06 & 1.71 \\
\hline 40 & 2.32 & 0.06 & 1.53 & 70 & 2.76 & 0.09 & 1.83 \\
\hline 50 & 2.21 & 0.05 & 1.46 & 100 & 2.82 & 0.13 & 2.21 \\
\hline 60 & 2.07 & 0.04 & 1.35 & & & & \\
\hline
\end{tabular}

The FTIR spectra of the materials obtained through impregnation using various amplitudes are provided in figure 3. In the IR spectra of these compounds $(\mathrm{c}-\mathrm{g})$ the absorption bands from $\left[\mathrm{OmimBF}_{4}\right]$ vibrational spectrum are found - the bands between $2960-2860 \mathrm{~cm}^{-1}$ are characteristics of the stretching vibrations of $\mathrm{CH}_{3}$ and $\mathrm{CH}_{2}$; the imidazolium $\mathrm{CH}$ stretching: $3158 \mathrm{~cm}^{-1}$, $3125 \mathrm{~cm}^{-1}$; the bands between $850 \mathrm{~cm}^{-1}-740 \mathrm{~cm}^{-1}$ are attributed to stretching vibrations of $\mathrm{BF}_{4}$ anion [26]. The infrared spectra show that $\left[\mathrm{OmimBF}_{4}\right]$ was impregnated in the highest quantity when $100 \%$ amplitude of ultrasonication was used.

\subsection{Adsorption of $\mathrm{Cs}^{+}$from aqueous solutions}

The results regarding the $\mathrm{Cs}^{+}$uptake by the materials obtained at various impregnation times and at various amplitudes of ultrasonication are presented in figure 4. It can be noticed that through increasing the impregnation time, random results are obtained. The increasing time of impregnation didn't lead to an increase of the $\mathrm{Cs}^{+}$uptake. These results were obtained because increasing the impregnation time leads to a conglomeration of the $\left[\mathrm{Omim} \mathrm{BF}_{4}\right]$ particles onto the surface of Florisil and the adsorbents obtained at higher impregnation times 


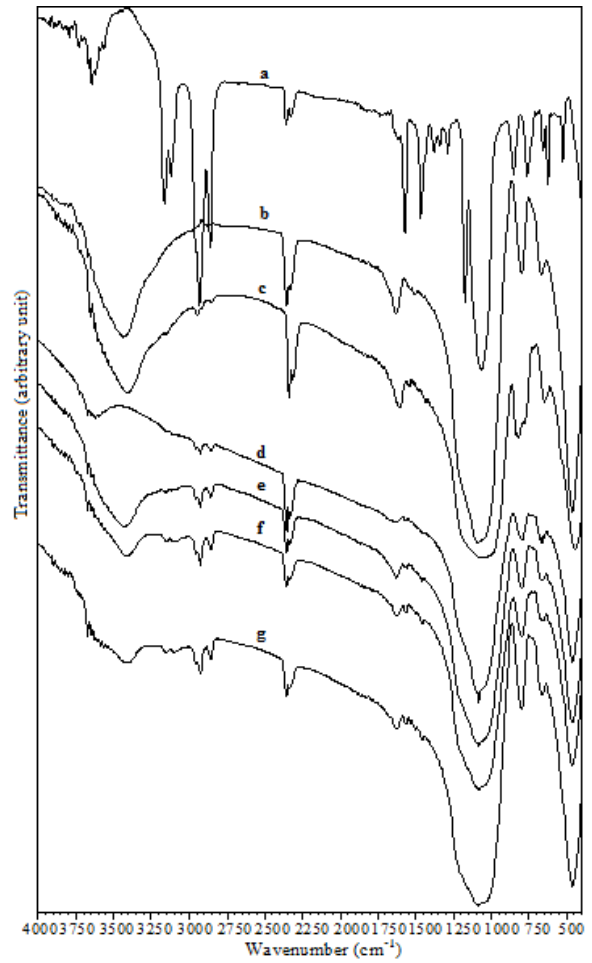

Figure 3: The FTIR spectra of the a) [Omim $\left.\mathrm{BF}_{4}\right]$; b) Florisil before impregnation; c) Florisil impregnated at 10\%; d) Florisil impregnated at $30 \%$; e) Florisil impregnated at $50 \%$; f) Florisil impregnated at $70 \%$; g) Florisil impregnated at $100 \%$.
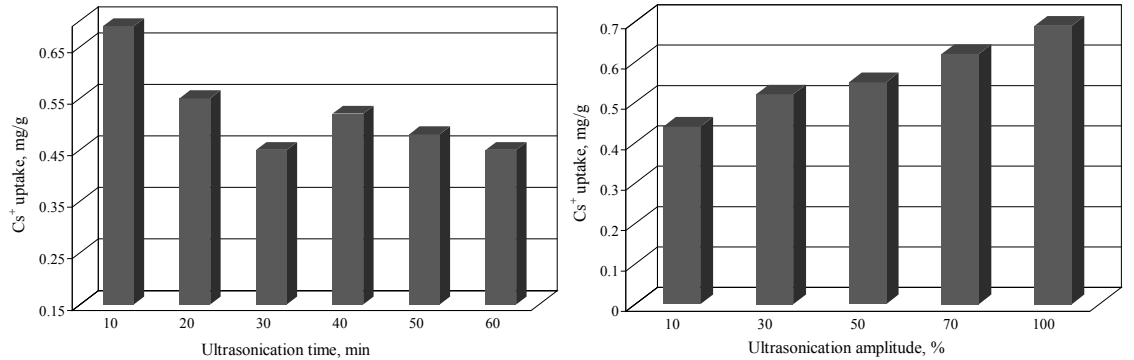

Figure 4: $\quad \mathrm{Cs}^{+}$uptake versus the ultrasonication work conditions.

are not homogenous. By increasing the ultrasonication amplitude an adsorbent is obtained which develops higher adsorption efficiency in the removal process of $\mathrm{Cs}^{+}$from aqueous solutions. The most efficient adsorbent in the removal process of $\mathrm{Cs}^{+}$from a $10 \mathrm{mg} / \mathrm{L}$ solution proved to be the Florisil impregnated with 
[OmimBF 4$]$ using a $100 \%$ amplitude of ultrasonication for 10 minutes. This result is in accordance with the conclusions drawn from the materials characterizations section.

The material obtained in the recommended conditions of impregnation (10 minutes of ultrasonication at amplitude of $100 \%$ ) was treated with $\mathrm{Cs}^{+}$ aqueous solutions having various concentrations $(5-50 \mathrm{mg} / \mathrm{L})$ in order to determine its maximum adsorption capacity. The experimental data were fitted with the Langmuir and Freundlich isotherm and the results are presented in figure 5 .

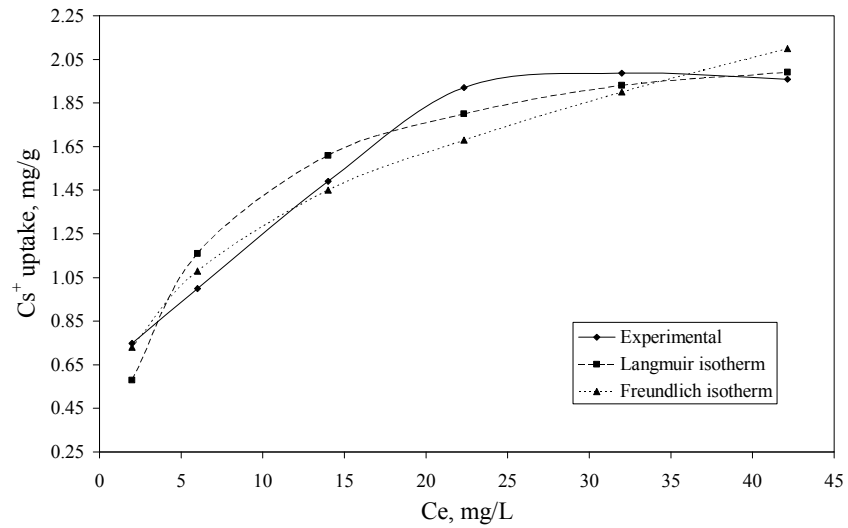

Figure 5: Adsorption isotherms of $\mathrm{Cs}^{+}$onto Florisil impregnated with $\left[\mathrm{OmimBF}_{4}\right]$.

From the experimental data it can be observed that $\mathrm{Cs}^{+}$uptake increases with the increase of the equilibrium concentration of $\mathrm{Cs}^{+}$, and then it approaches a constant value. The Freundlich isotherm has a lower regression coefficient $\left(\mathrm{R}^{2}=0.9663\right)$ compared with the Langmuir isotherm $\left(\mathrm{R}^{2}=0.9914\right)$. The constant $K_{F}$ can be defined as an adsorption coefficient which represents the quantity of adsorbed metal ions for a unit equilibrium concentration; in our case $\mathrm{K}_{\mathrm{F}}=0,575 \mathrm{mg} / \mathrm{g} . \quad 1 / \mathrm{n}$ is a measure of the adsorption intensity or surface heterogeneity. For $1 / \mathrm{n}=1$, the partition between the two phases is independent of the concentration. The situation $1 / \mathrm{n}<1$ is the most common and corresponds to a normal L-type Langmuir isotherm, whilst $1 / \mathrm{n}>1$ is indicative of a cooperative adsorption which involves strong interactions between the molecules of an adsorbate. $1 / \mathrm{n}$ obtained in this case is 0.352 showing favorable adsorption of $\mathrm{Cs}^{+}$ions onto the Florisil impregnated with $\left[\mathrm{OmimBF}_{4}\right]$. It can be mentioned that the Langmuir model effectively describes the sorption data of $\mathrm{Cs}^{+}$onto the studied adsorbent due to the higher correlation coefficient and due to the obtained maximum adsorption capacity (2.27 $\mathrm{mg} \mathrm{Cs} / \mathrm{g}$ adsorbent) which is closer to those obtained experimentally ( $2 \mathrm{mg} \mathrm{Cs}^{+} / \mathrm{g}$ adsorbent). 


\section{Conclusions}

The present paper showed that the work condition of the ultrasonication impregnation method is important in order to enhance the adsorption capacities of the resulting adsorbents. In order to obtain a stable and homogenous impregnation of the solid support surface, which will achieve reproducible results in the adsorption processes, it is not necessary to increase the ultrasonication time, but we should use a higher amplitude. In this way, the studied ionic liquid $\left[\mathrm{OmimBF}_{4}\right]$ adhered inside the cavities of the Florisil, not only at the surface. Therefore, the ultrasonication method is an efficient method of impregnation because a shorter time and smaller quantity of ionic liquids is used and the loss of the IL in the aqueous phase is avoided. The impregnated material obtained in the recommended conditions showed good adsorption performance in the removal process of $\mathrm{Cs}^{+}$from aqueous solutions, developing a maximum adsorption capacity of $2.27 \mathrm{mg} / \mathrm{g}$.

\section{Acknowledgement}

This work was supported by a grant of the Romanian National Authority for Scientific Research, CNCS - UEFISCDI, project number PN-II-RU-TE-2012-30198 .

\section{References}

[1] Xu, C., Shen, X., Chen, Q., Gao, H., Investigation on the extraction of strontium ions from aqueous phase using crown ether-ionic liquid systems. Science in China Series B: Chemistry, 52(11), pp. 1858-1864, 2009.

[2] Nilchi, A., Saberi, R., Moradi, M., Azizpour, H., Zarghami, R., Adsorption of caesium on copper hexacyanoferrate-PAN composite ion exchanger from aqueous solution. Chemical Engineering Journal, 172, pp. 572-580, 2011.

[3] El-Kamash, A.M., Evaluation of zeolite A for the sorptive removal of $\mathrm{Cs}^{+}$ and $\mathrm{Sr}^{2+}$ ions from aqueous solutions using batch and fixed bed columns operations. Journal of Hazardous Materials, 151, pp. 432-445, 2008.

[4] Abd El-Latif, M.M., Elkady, M.M., Kinetics study and thermodynamic behaviour for removing caesium, cobalt and nickel ions from aqueous solution using nano-zirconiuim vanadate ion exchange. Desalination, 271, pp. 41-54, 2011.

[5] Lupa, L., Negrea, A., Ciopec M., Negrea, P., $\mathrm{Cs}^{+}$removal from aqueous solutions through adsorption onto Florisil impregnated with trihexyl(tetradecyl) phosphonioum chloride, Molecules, 18(10), pp. 12845-12856, 2013.

[6] Sun, X., Li, Y., Chen, J., Ma, J., Solvent impregnated resin prepared using task-specific ionic liquids for rare earth separation. Journal of Rare Earths, 27(6), pp. 932-936, 2009. 
[7] Liu, Y., Zhu, L., Sun, X., Chen, J., Luo, F. Silica materials doped with bifunctional ionic liquid extractants for Yttrium extraction. Industrial \& Engineering Chemistry Research, 48, pp. 7308-7313, 2009.

[8] Guo, L., Liu, Y., Zhang, C., Chen, J., Preparation of PVDF-based polymer inclusion membrane using ionic liquid plasticizer and Cyphos IL 104 carrier for $\mathrm{Cr}(\mathrm{VI})$ transport. Journal of Membrane Science, 372, pp. 314-321, 2011.

[9] Mahmoud, M. E., Surface loaded 1-methyl-3-ethylimidazolium bis (tri fluoro methyl sulfonyl) imide [EMIM $\left.{ }^{+} \mathrm{Tf}_{2} \mathrm{~N}^{-}\right]$hydrophobic ionic liquid on nano-Silica sorbents for removal of lead from water samples. Desalination, 266, pp. 119-127, 2011.

[10] Zhu, L., Guo, L., Zhang, Z., Chen, J., Zhang, S., The preparation of supported ionic liquids (SILs) and their application in rare metals separation. Science China Chemistry, 55(8), pp. 1479-1487, 2012.

[11] Lemus, J., Palomar, J., Gilarranz, M., Rodriquez, J., Characterization of supported ionic liquid phase (SILP) materials prepared from different supports. Adsorption, 17(3), pp. 561-571, 2011.

[12] Negrea, A., Lupa, L., Ciopec M., Negrea, P., Characterization of strontium adsorption from aqueous solutions using inorganic materials impregnated with ionic liquid, International Journal of Chemical Engineering and Applications, 4(5), pp. 326-331, 2013.

[13] Negrea, A., Ciopec, M., Lupa, L., Negrea P., Gabor, A., Influence of the solid support base impregnated with IL on the sorption of various radionuclides from aqueous solutions, AWER Procedia Advances in Applied Science, 1, pp. 241-250, 2013.

[14] Gallardo, V., Navarro, R., Saucedo, I., Avila, M., GUIBAL, E., Zinc(II) extraction from hydrochloric acid solutions using Amberlite XAD7 impregnated with Chyphos IL101 (tetradecyl(trihexyl) phosphonium chloride). Separation Science and Technology, 43, pp. 2434-2459, 2008.

[15] Guibal, E., Pinol, A.F., Ruz, M., Vincent, T., Jounanin, C., Sastre, A., Immobilization of Chypos ionic liquids in alginate capsules for $\mathrm{Cd}$ (II) sorption. Separation Science and Technology, 45, pp. 1935-1949, 2010.

[16] Liu, Y., Sun, X., Luo, F., Chen, J., Preparation of sol-gel materials doped with ionic liquids and thrialkyl phosphine oxides for Yttrium(III) uptake. Analytical Chimica Acta, 604, pp. 107-113, 2007.

[17] Zhu, L., Liu, Y., Chen, J., Synthesis of N-methyimidazolium functionalized strongly basic anion exchange resins for adsorption of Cr(VI). Industrial \& Engineering Chemical Research, 48, pp. 3261-3267, 2009.

[18] Zhu, L., Zhang, C., Liu, Y., Wang, D., Chen, J., Direct synthesis of ordered N-methylimidazolium functionalized mesoporous Silica as highly efficient anion exchanger of Cr(VI). Journal of Materials Chemistry, 20, pp. 1553-1559, 2010.

[19] Kalidhasan, S., Kumar, A.S.K., Rajesh, V., Rajesh N., An efficient ultrasound assisted approach for the impregnation of room temperature ionic liquid onto Dowex 1x8 resin matrix and its application toward the 
enhanced adsorption of $\mathrm{Cr}(\mathrm{VI})$. Journal of Hazardous Materials, 213214, pp. 249-257, 2012.

[20] Zhou, X., Chen, Q., Tao, Y., Weng, H., Influence of ultrasound impregnation on the performance of $\mathrm{Co} / \mathrm{Zr} / \mathrm{SiO}_{2}$ catalyst during FischerTropsch synthesis, Chinese Journal of Catalysis, 32(6-8), pp. 1156-1165, 2011.

[21] Zhang, Y., Zhao, X., Xu, H., Shen, K., Zhou, C., Jin, B., Sun, K., Novel ultrasonic-modified $\mathrm{MnO}_{\mathrm{x}} / \mathrm{TiO}_{2}$ for low-temperature selective catalytic reduction (SCR) of NO with ammonia, Journal of Colloid and Interface Science, 361(1), pp. 212-218, 2011.

[22] Negrea, A., Lupa, L., Ciopec, M., Negrea, P., Vodă, R., Ianasi, C. Study of different impregnation methods of inorganic supports with ionic liquid, Journal of Environmental Protection and Ecology, 14(4), pp. 1785-1793, 2013.

[23] Keskin, S., Kayrak-Talay, D., Akman, U., Hortacsu, O., A review of ionic liquids toward supercritical fluid applications, Journal of Supercritical Fluids, 43, pp. 150-180, 2007.

[24] Khupse, N.D., Kumar, A., Ionic liquids: New materials with wide applications, Indian Journal of Chemistry, 49A, pp. 653-648, 2010.

[25] Zhao, H., Xia, S., Ma, P., Review Use of ionic liquids as "green" solvent for extraction, Journal of Chemical Technology and Biotechnology, 80, 1089-1096, 2005.

[26] Buffeteau, T., Grondin, J., Lassègues, J.C., Infrared spectroscopy of ionic liquids: Quantitative aspects and determination of optical constants. Applied Spectroscopy, 64(1), pp. 112-119, 2010. 